\title{
Relationship between Patient Safety Culture and Adverse Events in Hospital: A case study
}

\author{
Hojatolah Gharaee ${ }^{1}(\mathbb{D})$, Razie Jahanian ${ }^{2}(\mathbb{D})$, Majid Hosseini Karim $^{3}$ (D), Edris Kakemam ${ }^{4}$ (D), \\ Abstract $\quad K^{2}$ hadijeh Bande Elahi ${ }^{5}$ (D), Leili Tapak ${ }^{6}$ (D), Yadolah Hamidi ${ }^{7 *}$ (D)
}

Introduction: Patient safety culture is an important factor in reducing hospital's adverse event and improving patient safety. The aim of this study was to evaluate the relationship between patient safety culture and adverse events in hospitals of Hamadan city.

Methods: The present study was a descriptive-analytical study which was performed in hospitals of Hamadan in 2018. The study population consisted of nurses working in hospitals. The patient safety culture questionnaire and adverse event checklist were used for data collection. Questionnaires were completed by 650 nurses. Multiple logistic regression was used to examine the relationship between the variables.

Results: The highest mean score of patient safety culture was related to the dimension of organizational learning, and the lowest score was for exchange and transfer of information. 35.4 percent of nurses said they had seen at least one patient fall in the past year (the least adverse event). Moreover, 51.9 percent of nurses stated that at least one pressure ulcer, or a complaint by a patient or his/her family had happened at their workplace in the past year (the most adverse event). Finally, the mean score of the patient safety culture had a significant relationship with the incidence of adverse events.

Conclusion: This study confirms the patient safety culture as a predictor of adverse events. Hence, health officials and hospital administrators should provide prerequisites for promoting patient safety culture and reducing adverse events through different strategies, such as encouraging adverse events reporting as well as holding nurse training courses.

Keywords: Patient Safety Culture, Adverse Events, Hospital

- Received: 28/Jan/2020 Modified: 04/March/2020 • Accepted: 15/March/2020

1. Public Health Master, Hamadan University of Medical Sciences, Hamadan, Iran; gharaee.hojat@ gmail.com

2. School Health Master, Hamadan University of Medical Sciences, Hamadan, Iran; r.jahaniean@yahoo.com

3. M.Sc. Student, School of engeeneering, Buali-Ali Sina University, Hmadan, Iran; hosseinikarim.majid@gmail.com

4. PhD Candidate, School of Management and Medical Informatics, Tabriz University of Medical Sciences, Tabriz, Iran; edris_kakemam@yahoo.com

5. Health Education Master, Asadabad School of Medical Sciences, Asadabad, Iran; bandehalahi@gmail.com

6. Assistant Professor, School of Public Health, Modeling of Noncommunicable Diseases Research Center,

Hamadan University of Medical Sciences, Hamadan, Iran; L.tapak@umsha.ac.ir

7. Associate Professor, School of Public Health, Research Center for Health Sciences, Hamadan University of Medical

Sciences, Hamadan, Iran; Corresponding Author, Hamidi@umsha.ac.ir 


\title{
رابطه فرهنَ ايمنى بيمار و حوادث ناخواسته در بيمارستان: مطالعه موردى
}

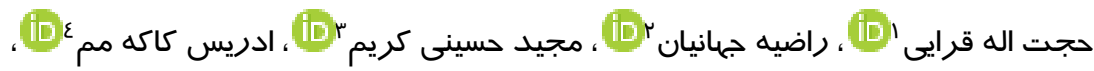

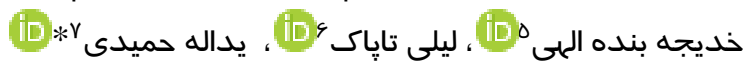

ק्रيده

مقدمه: فرهنگ ايمنى بيمار يك عامل مهم در تلاش براى كاهش حوادث ناخواسته در بيمارستان و ارتقاى ايمنى بيمار است.

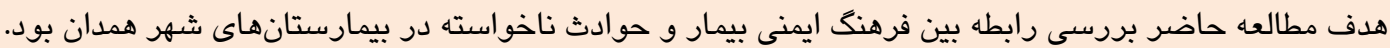

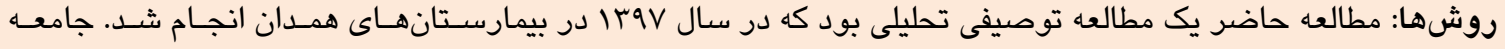

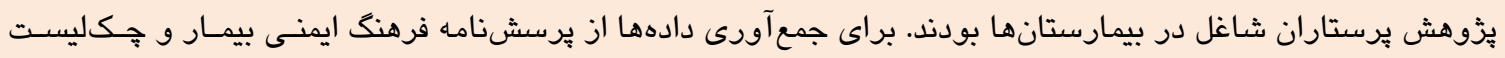

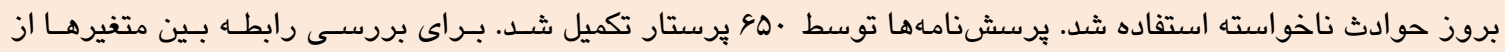

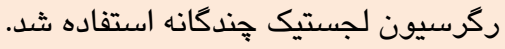

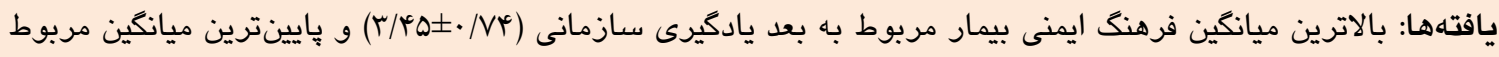

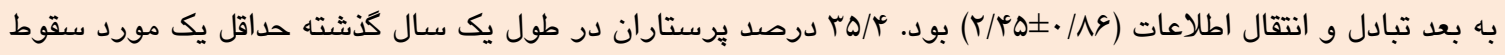

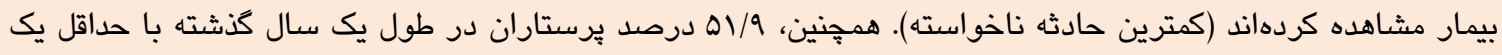

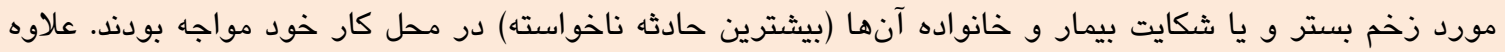

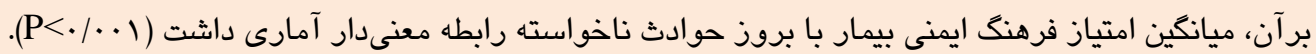

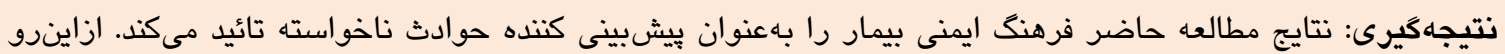

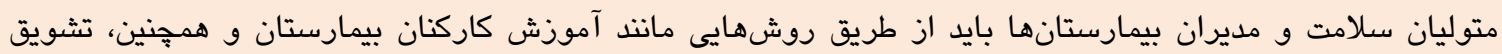

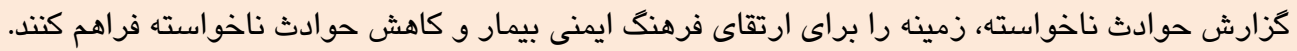

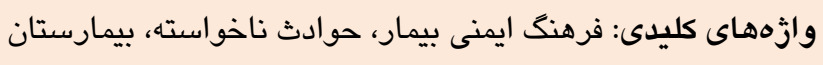

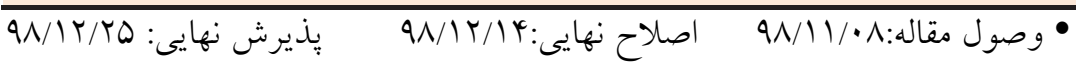

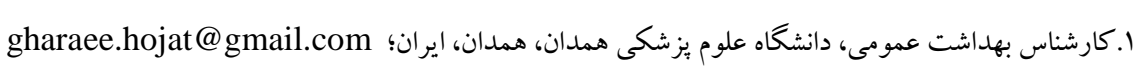

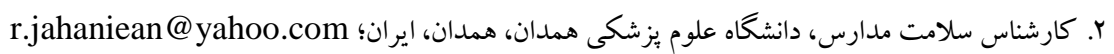

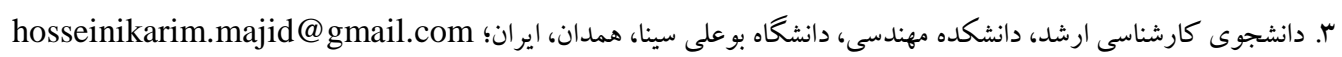

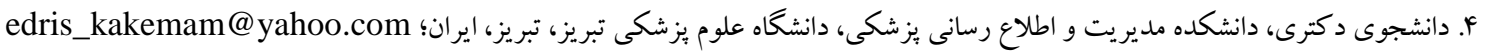

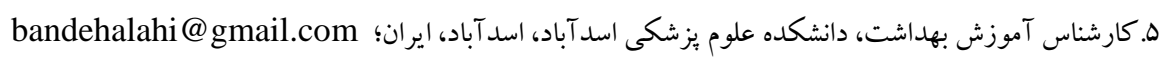

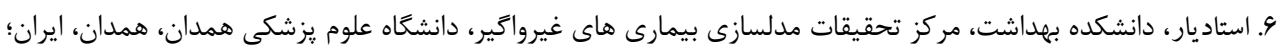


يرستاران و يز شكان اتفاق مىافتد و ادعا مى كند كه خطاهاى سيستم كه ناشى از مشكلات مديريت، محيط كار و كار كنان هستند، جنبه مهمى از حوادث ناخواسته قابل ييشخيرى هستند. [YI [ازنجايى كه خطاهاى فردى اجتنابنايذير هستند لذا، تمركز از سرزنش افراد به بهبود سيستمها تغيير كرده است.

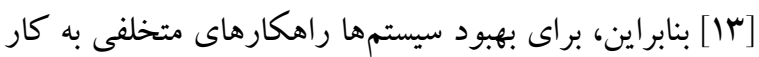
كرفتهشده است كه يكى از اين ابتكارات ارتقاى فرهنك بنك

$$
\text { ايمنى بيمار است. [IF] }
$$
فرهنك ايمنى بيمار در سازمانهاى مراقبت سلامت بهويثه إنها بيمارستانها شامل ارتباطاتى است كه بر اساس اعتماد متقابل، مركال

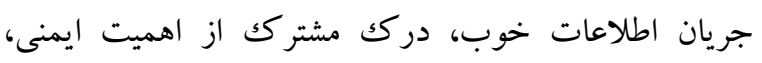

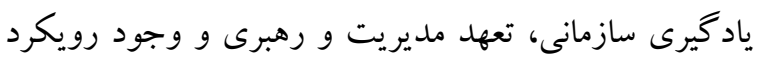

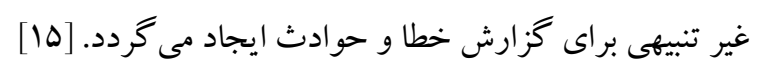

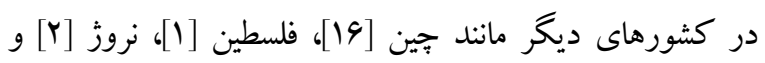

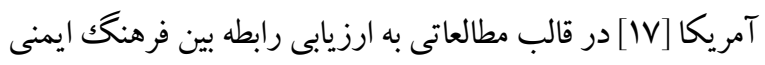
بيمار و حوادث ناخواسته برداختهاند كه نشاندهنده اهميت و تأثير إني فرهنك ايمنى بيمار بر بروز حوادث ناخواسته است.

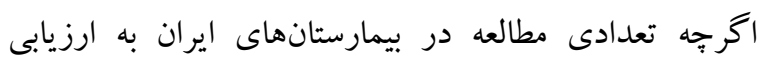

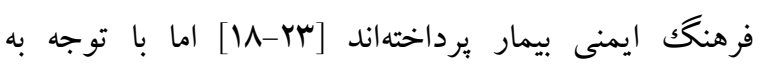

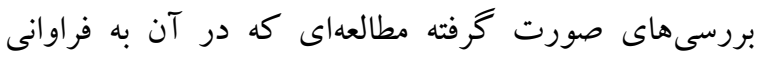

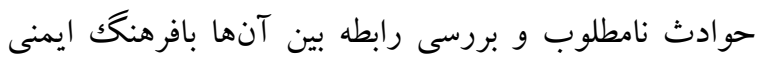

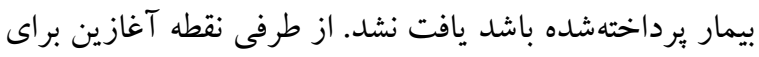

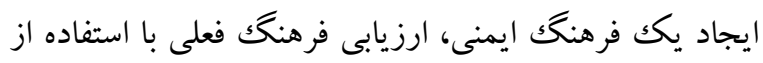

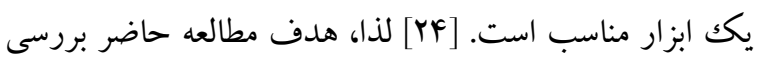

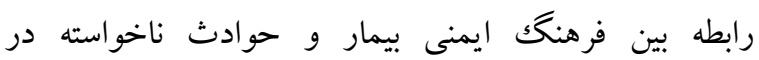

$$
\text { بيمارستانهاى شهر همدان بود. }
$$

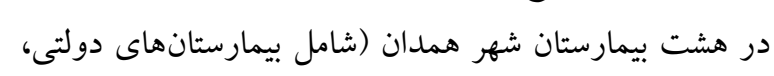
خصوصى، خيريه و تأمين اجتماعى) انجام شد. جامعه يزٔوهش يرستاران شاغل در اين بيمارستانها بود. با توجه به اينكه ازلحاظ آمارى برستاران بيشترين تعداد اعضاى كادر درمان را

\section{روشها}

مطالعه حاضر از نوع توصيفى تحليلى است كه در سال Irav$$
\text { تشكيل مىدهند و بيشتر از ساير كادر درمانى بيمارستان }
$$

\section{مقدمه}

ايمنى بيمار بهعنوان محور كيفيت مراقبتهاى سلامت در نظر

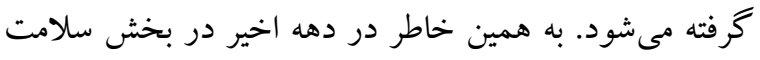

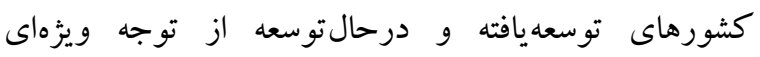
برخوردار بوده است. بروز مداوم حوادثى كه به بيماران آسيب

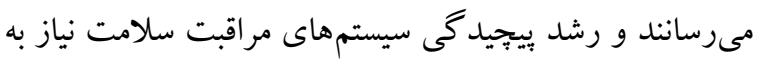

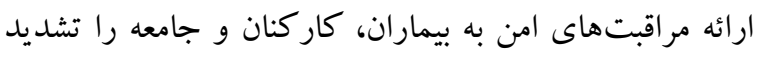

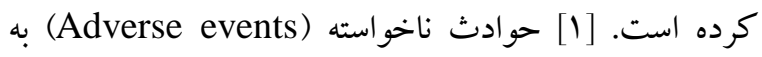
دليل خطاهاى فردى و ضعف سيستم در ارائه خدمات سلامت،

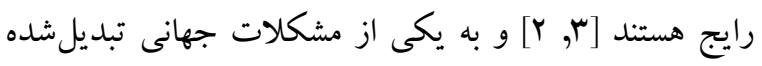

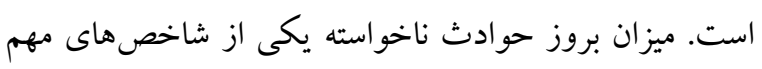

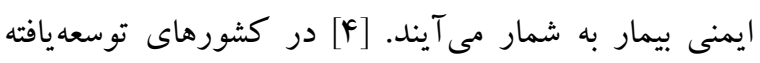

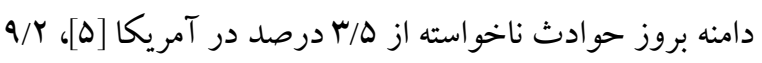

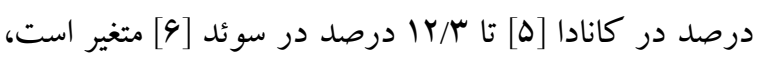
درحالى كه ميزان گزارش حوادث ناخواسته در مطالعهاى در ايران براى عفونت خون، زخم بستر، سقوط بيمار و عفونت مير دران

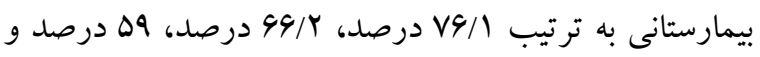

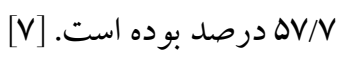

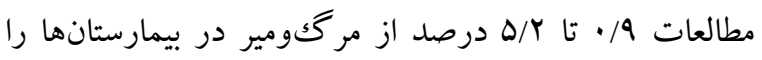

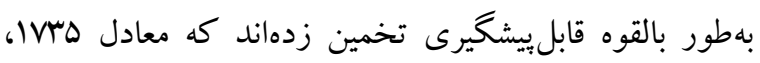

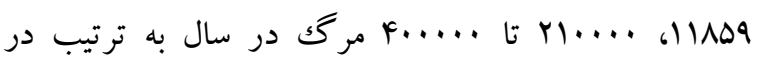

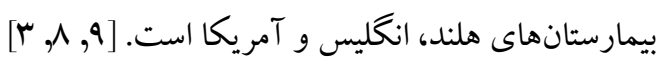

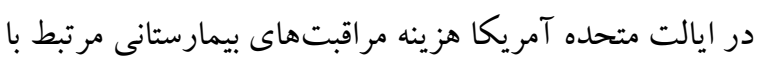

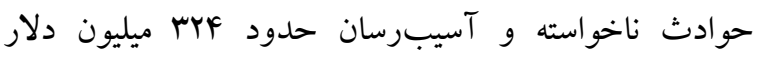
بر آورد شده است. هزينههاى مربوط به حوادث قابل يشخيشى

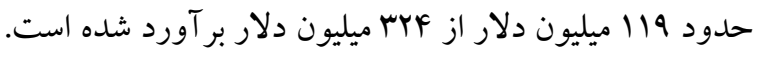
[·1] در مطالعهاى توسط هونهات و همكاران در هلند هزينهاى مستقيم سالانه هذه ميليون يورو براى همه حوادث

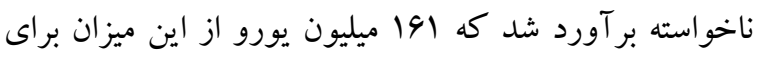

حوادث ناخو استه قابل بيشخيرى بود. [11] موسسه يزشكى (The Institute of Medicine) آمريكا اشاره مى كند كه حوادث ناخواسته قابل ييشخيرى علاوه بر

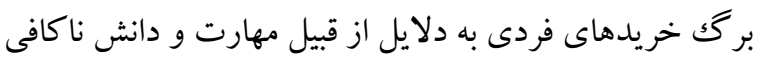


بهوسيله آزانس كيفيت و تحقيقات مراقبت سلامت طراحى گرديد و تاكنون بارها براى ارزيابى فرهنگك ايمنى بيمار در نقاط مختلف دنيا به كار گرفتهشده است. اين برسشنامه در

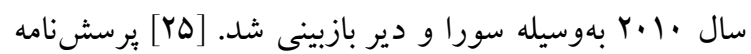

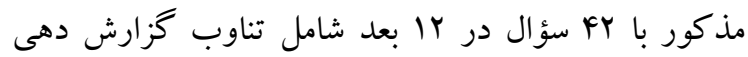
رخداد، يادگيرى سازمانى، باز بودن مجارى ارتباطى، حمايت مديريت از كاركنان، ارتباطات و ارائه بازخورد در مورد خطاها، بِاسخ غير تنبيهى در قبال رويداد خطا (هر كدام سه سؤال) و دركك كلى از ايمنى بيمار، حمايت مديريت از ايمنى بيمار، كار تيمى درون واحدهاى سازمانى، مسائل مربوط به كاركنان، كار تيمى بين واحدهاى سازمانى، تبادلات و انتقال اطلاعات (هركدام جهار سؤال) فرهنك بهى

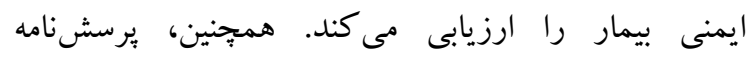

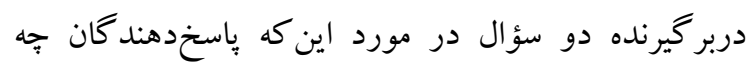
نمرهاى براى ايمنى بيمار در بخش و بيمارستان در نظر

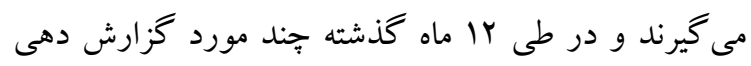
خطا داشتهاند، است. اين برسشنامه توسط محققان ايرانى به زبان فارسى ترجمه شد و در مطالعه مقرى و همكاران روايى و يايايى آن تائيد شد [צr] كه ضريب آلفاى كرونباخ ابعاد

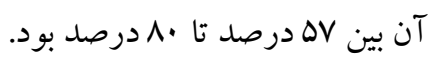
براى نمره گذارى سؤالات برسشنامه از طيف ليكرت ينج

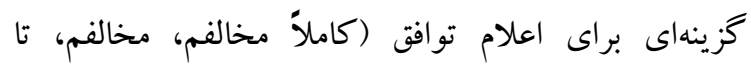

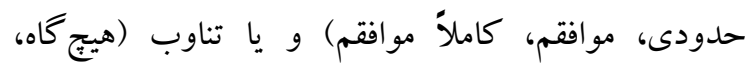
بهندرت، كاهى اوقات، اغلب، هميشه) استفاده شد كه به ترتيب امتياز يكك تا ينج گرفتهاند. ميانگين امتياز فرهنگك ايمنى بيمار و هر حيطه نيز بين يكك تا ينج محاسبه شد. براى

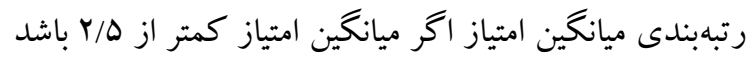

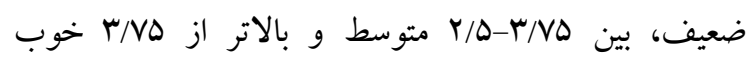
ارزيابى مى كردد. براى نمره گذارى دو سؤال در مورد اين كه باسخدهند گردان بهوركلى جه نمرهاى براى ايمنى بيمار در بخش و ولى

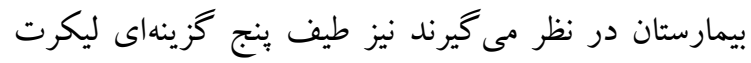
(خيلى ضعيف، ضعيف، خوب، خيلى خوب) به كاربرده شد.
ازجمله يزشكان با بيماران در تماس هستند و متعاقباً بيشتر در جريان اتفاقات رخداده در طول مراقبت از بيمار هستند، در مطالعه حاضر از يرستاران بهعنوان شركت كننده در مطالعه استفادهشده است. معيار ورود به مطالعه حداقل داشتن يكك سال سابقه كار در حوزه خدمات بالينى و حداقل داشتن مدر كك ليسانس بود. حجم نمونه بر اساس ضريب همبستى سار/ م و با در نظر كرفتن خطاى ه/· و توان آزمون ·9 درصدى برابر يرستار به دست آمد. با فرض نرخ پياسخ گويى هـ.٪ يرستاران VII توزيعشده توسط 994 يرستار تكميل و باز گردانده شد. بدين ترتيب نرخ بِاسخدهى به يرسشنامههاى توزيعشده برابر بـ درصد بود. در اين مطالعه روش نمونه گيرى بهصورت جندمرحلهاى بود.

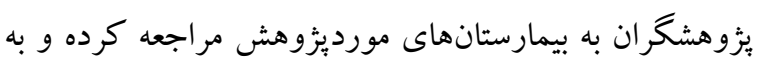
نسبت تعداد برستار شاغل در هر بخش تعداد افراد موردمطالعه از هر بخش را تعيين كردند. سيس بزگوهشخران در دو نوبت صبح و عصر به بخشها مراجعه كرده و به روش نمونه گيرى در دسترس از بين يرستاران حاضر در بيمارستان شركت كنند كان مطالعه را انتخاب نمودند. يس از انتخاب شركت كنند كان در مورد هدف از انجام مطالعه توضيحات لازم را ارائه داده و سيس به شر كت كنند گان اطمينان داده شد كه نتايج حاصل از مطالعه بدون نام و مشخصات آنها منتشر خواهد شد. به برستاران يكك هفته فرصت داده شد كه برسشنامه ها را تكميل نمايند. ابزار مورداستفاده در بُزوهش حاضر پِرسشنامه سهبخشى بود. بخش اول شامل متغيرهاى جمعيت شناختى و سازمانى از قبيل سن، جنس، وضعيت تأهل، سطح تحصيلات، بخش محل كار و ميزان ساعت كار در هفته بود. بخش دوم مربوط به ارزيابى فرهنگ ايمنى بيمار بود كه براى ارزيابى آن از يرسشنامه استاندارد بيمايش بيمارستان در مورد فرهنگ ايمنى بيمار ( Hospital Survey On Patient Safety Culture 
براى اين منظور شش حادثه نامطلوب به دو گروه صفر =هر خز حادثه اتفاق رخ نداده است و يكك= اتفاق رخداده است (از قبيل جندين بار در سال، يككبار در ماه، جندين بار در ماه، يككبار در

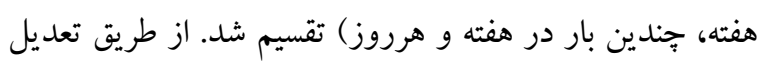

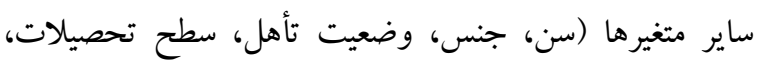
سابقه كار، بخش محل كار، ميزان ساعت كارى در هفته) در ورد مدل رگرسيون، اثر مخدوش گرى آنها كنترل شد.

\section{يافته ها}

\section{يافتهاى جمعيت شناختى}

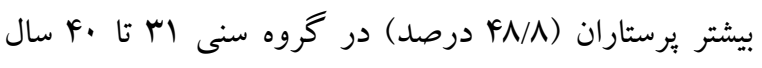

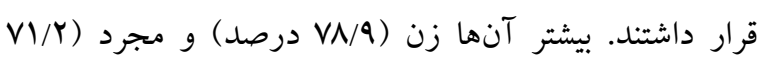

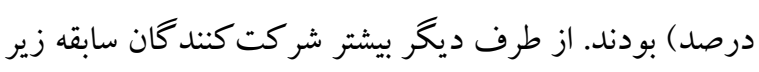

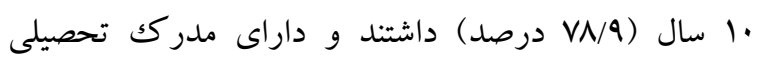

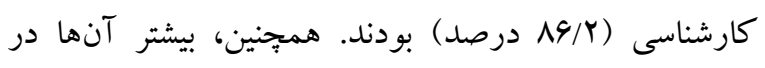

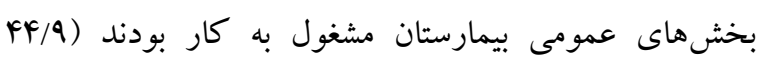

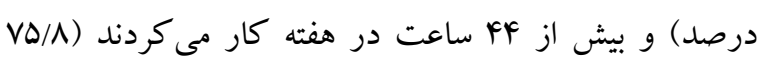

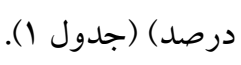

براى محاسبه ميانخين و رتبهندى دو سؤال مذكور نيز از

$$
\text { روشهاى بالا استفاده گرديد. }
$$

در مطالعه حاضر شش حادثه نامطلوب كه اغلب در بيمارستان رخ مىدهد [19,19] شامل زخم بستر (Pressure Ulcer)،

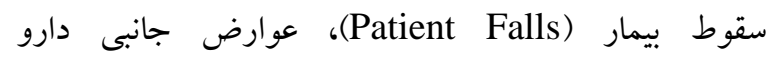
(Adverse Drug Events) (Surgical Wound Infection) خون (Infusion Or Transfusion Reaction) و شكايت Patients or their family ) بيماران يا خانوادههايشان

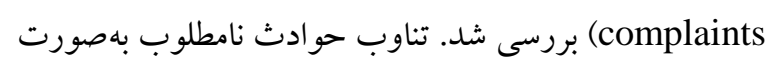

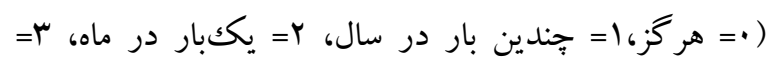

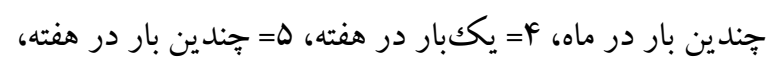
9- هر روز) درجهبندى شده است.

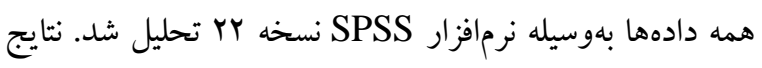

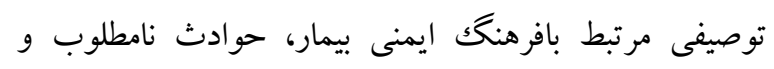

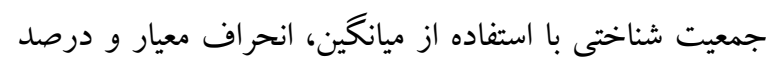

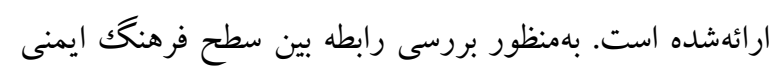

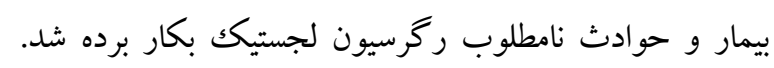

\begin{tabular}{|c|c|c|c|}
\hline درصد & تعداد & & \\
\hline$F Y / 9$ & $r W v$ & rI-r. & \multirow{3}{*}{ سن (سال) } \\
\hline FN/A & riv & rI- $F$. & \\
\hline N/9 & $\Delta 9$ & $\geq+1$ & \\
\hline$r M / l$ & ITV & مرد & \multirow{2}{*}{ 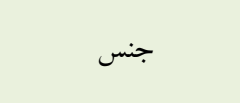 } \\
\hline$V N / 9$ & ه & زن & \\
\hline$V I / r$ & kar & مجرد & \multirow{2}{*}{ وضعيت تأهل } \\
\hline YN/A & IVA & متأهل & \\
\hline$V N / q$ & DIr & $<1$. & \multirow{2}{*}{ سابقه كار بالينى (سال) } \\
\hline$r M / l$ & ITV & $\geq 1$ & \\
\hline$\Lambda 9 / \Gamma$ & $\Delta 9$. & كارشناسى & \multirow{2}{*}{ سطح تحصيلات } \\
\hline $1 r / \Lambda$ & 9. & كارشناسى ارشد & \\
\hline$\mu \varphi /$. & rrI & مر اقبتهاى ويزّه & \multirow{3}{*}{ بخش محل كار } \\
\hline$r M / l$ & ITV & اورُّانس & \\
\hline$F F / q$ & rar & بخش هاى عمومى & \\
\hline$V \Delta / A$ & rar & 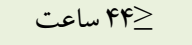 & ميزان ساعت كارى در \\
\hline$r F / r$ & $10 \mathrm{~V}$ & > & هفته \\
\hline $1 .$. & 90. & & كل \\
\hline
\end{tabular}

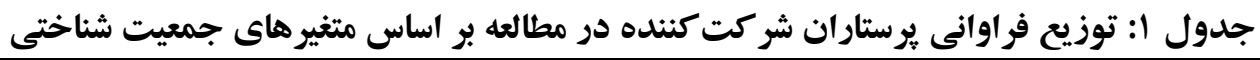




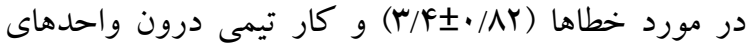
سازمانى ( ) ( فرهنك ايمنى بيمار در ابعاد تبادلات و انتقال اطلاعات

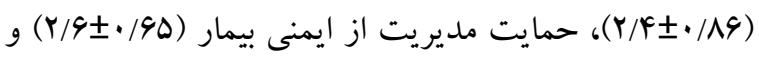

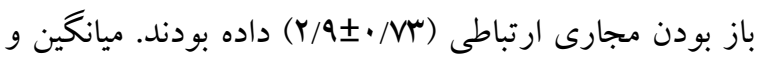
انحراف معيار ساير ابعاد در جدول دو ارائهده است.
ميانتين نمر ات ابعاد فر هنتك ايمنى بيمار

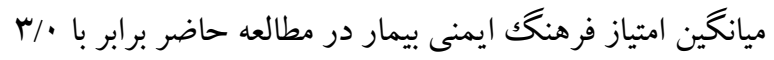
با انحراف معيار •/· بود كه نشاندهنده سطح متوسط فر هنگك ايمنى بيمار است. از بين ابعاد فرهنگ ايمنى بيمار بيشترين ميانگين مربوط به بعد المد ياد گيرى سازمانى (YFI/FF)، بعد ارتباطات و ارائه بازخورد

\begin{tabular}{|c|c|c|}
\hline انحر اف معيار & ميانكين & ابعاد فرهنك ايمنى بيمار \\
\hline$\cdot / V^{f}$ & $r / f$ & يادگيرى سازمانى \\
\hline$\cdot / \Lambda Y$ & $r / f$ & ارتباطات و ارائه بازخورد در مورد خطاها \\
\hline$\cdot / M$ & $r / f$ & كار تيمى درون واحدهاى سازمانى \\
\hline$\cdot / V^{F}$ & $r / l$ & حمايت مديريت از كار كنان \\
\hline$\cdot / A r$ & $r / 1$ & تناوب گزارش دهى رخداد \\
\hline$\cdot / 94$ & $r / 1$ & پِاسخ غير تنبيهى در قبال رويداد خطا \\
\hline$\cdot / \mathrm{Vq}$ & $\mu /$ & مسائل مربوط به كار كنان \\
\hline$\cdot / 91$ & $\mu /$ & كار تيمى بين واحدهاى سازمانى \\
\hline$\cdot 109$ & $\mu /$ & درك كلى از ايمنى بيمار \\
\hline$\cdot / M r$ & $r / q$ & باز بودن مجارى ارتباطى \\
\hline$\cdot 190$ & $r / 9$ & حمايت مديريت از ايمنى بيمار \\
\hline$\cdot / \wedge 9$ & $r / F$ & تبادلات و انتقال اطلاعات \\
\hline$\cdot / f$ & $\mu /$ & ايمنى كلى بيمار \\
\hline
\end{tabular}

نكردهاند. همجينين، اكثر يرستاران (4 949 درصد) مورد سقوط را در يكك سال گذشته بهصورت هر گز گزارش كردند. از طرف ديخر، بيشتر شر كت كنند گان مطالعه اظهار كردند كه در يكك سال گذشته هر گز تجربه مشاهده عوارض جانبى دارو (1/9 درصد)، عفونت زخم جراحى (ه//اه درصد)، واكنش به تزريق يا انتقال خون (Y/Yه درصد) و شكايت بيمار يا

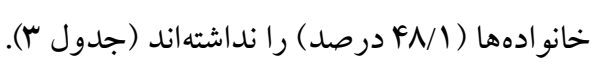

وضعيت فرهنگ ايمنى بيمار در بخش و بيمارستان بهطوركلى ميانگين امتياز وضعيت فرهنگك ايمنى بيمار از ديدكاه يرستاران بر اساس بِاسخ آنها به دو سؤال در مورد وضعيت كلى ايمنى بيمار در بخش و بيمارستان به ترتيب r/VF و حوادث ناخواسته بيشترين تعداد شركت كنند كان (FN/I درصد) عنوانه كه در طول يكك سال كذشته هر زز زخم بستر مشاهده

جدول rّ: فراوانى حوادث ناخواسته در يك سال حذشته در بيمارستانهاى شهر همدان از ديد كاه يرستاران

\begin{tabular}{|c|c|c|c|c|c|c|c|}
\hline هرووز & جار دندين & يككبار در & جار در ماه & يككبار در & جّندين بار & هركز & \\
\hline $1(\% \cdot / F)$ & $F(\% / / \Delta)$ & $r(\% / r)$ & If $(\% / \Delta / F)$ & $r \cdot(\% / V / V)$ & $a r(\% / \Delta / \Lambda)$ & $I r \Delta(\% F N / 1)$ & زخم بستر \\
\hline $1(\% \cdot / q)$ & $1(\% \cdot / \mathbb{f})$ & $r(\% \cdot / \Lambda)$ & $\mathrm{V}(\% / \mathrm{Y} / \mathrm{V})$ & $r(\% / . \wedge / \Lambda)$ & $\Delta \wedge(\%, Y r / r)$ & $191(1.94 / 9)$ & سقوط از تخت \\
\hline
\end{tabular}


حجت اله قرايى و همكاران

\begin{tabular}{|c|c|c|c|c|c|c|c|}
\hline $1(\% \cdot / 4)$ & $1(\% \cdot / 4)$ & $1(\% \cdot / 4)$ & $V(/ / Y / V)$ & $r(/ / N / 1)$ & $9 \Delta(/ . r 9 / \Delta)$ & $1 r \Delta(/ . \Delta 1 / 9)$ & عوارض جانبى دارو \\
\hline \multicolumn{8}{|c|}{ جدول rّ: (ادامه) } \\
\hline هروز & جار درين & يككبار در & جار در ماه & $\begin{array}{c}\text { يككبار دمر } \\
\text { يكاه }\end{array}$ & جّند سال بار & هركز & \\
\hline $1(\% / 4)$ & $1(\% \cdot \cdot / 4)$ & $r(\% / r)$ & $10(/ / . \Delta / \Lambda)$ & $r(/ / N / \Lambda)$ & $\wedge \Gamma(/ / r / / q)$ & $\operatorname{IrF}(/ / \Delta / / \Delta)$ & عفونت زخم جراحى \\
\hline $1(\% \cdot / 4)$ & $1(\% \cdot / 4)$ & $r(\% / \wedge)$ & $F(\% 1 / \Delta)$ & $r \Delta(/ 9 / 9)$ & $V(\%(/ r N / I)$ & $1 \Delta F(/ \Delta Q / Y)$ & واكنش به تزريق يا انتقال خون \\
\hline $1(\% \cdot / 4)$ & $\wedge(\% / \mu / 1)$ & $r(\% / r)$ & $r F(/ / 9 / r)$ & $10(\% / . / 1)$ & $\lambda F(\% / r / \Gamma)$ & ITD $(\%$ Y N/I $)$ & نكايت بيماران يا خانو اده آنها \\
\hline
\end{tabular}

ايمنى بيمار و تمامى حوادث ناخواسته ارتباط معنادار وجود

رابطه بين ابعاد فرهنك ايمنى بيمار و حوادث

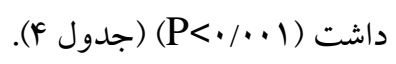

ناخواسته

با كنترل متغيرهاى جمعيت شناختى برستاران و ساير متغيرها

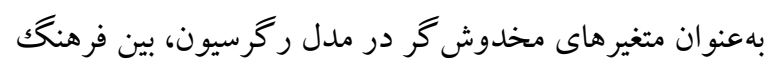

جدول f: ركر سيون لجستيك رابطه بين ابعاد فرهنك ايمنى بيمار و حوادث ناخواسته در يكك سال كذشته در بيمارستانهاى شهر همدان از ديد

\begin{tabular}{|c|c|c|c|}
\hline P-value & $95 \% \mathrm{CI}$ & ضريب مدل ركر سيون (B) & متغيرها \\
\hline $\mathrm{P}<\cdot / \cdot \cdot 1$ & $(\cdot /$ TYG-・/4NI) & . /TYa & زخم بستر \\
\hline $\mathrm{P}<\cdot / \cdot \cdot \mathrm{l}$ & $(\cdot / r+\wedge-\cdot / \& 99)$ & . /KFF & سقوط از تخت \\
\hline $\mathrm{P}<\cdot / \cdot \cdot 1$ & $(\cdot / / 91-\cdot / 9 \cdot 1)$ & - / FrG & عوارض جانبى دارو \\
\hline $\mathrm{P}<\cdot / \cdot \cdot \mathrm{l}$ & $(\cdot / r \mid r-\cdot / \& \Delta r)$ & . & عفونت زخم جراحى \\
\hline $\mathrm{P}<\cdot / \cdot .1$ & $(\cdot / r+\Delta-\cdot / q q 1)$ & $\cdot / \mu F$ & واكنش به تزريق يا انتقال خون \\
\hline $\mathrm{P}<\cdot / \cdot \cdot \mathrm{l}$ & $(\cdot / T Y Q-\cdot / F \wedge F)$ & 酒/ & شكايت بيماران يا خانواده آنها \\
\hline
\end{tabular}

بيمارستان و تناوب گزارش دهى حوادث ناخواسته اختصاص

$$
\text { داشت. }
$$

بر اساس يافتهاى مطالعه از بين ابعاد فرهنگك ايمنى بيمار

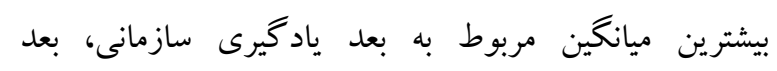

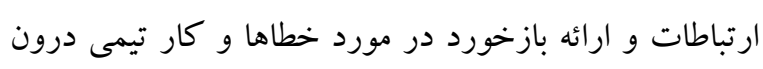

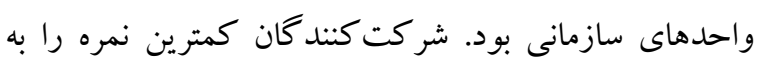

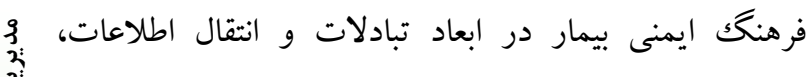

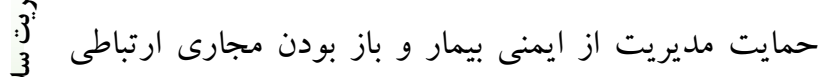

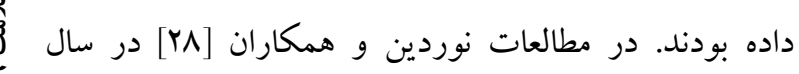

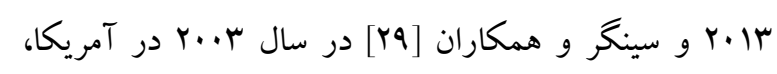

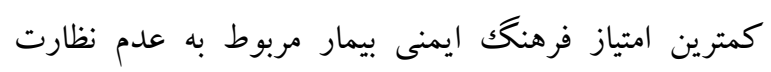

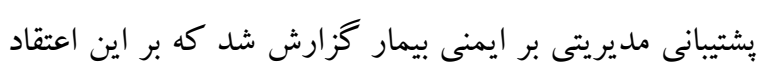

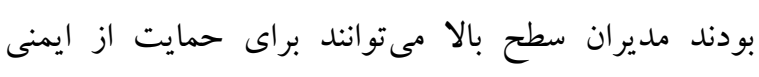

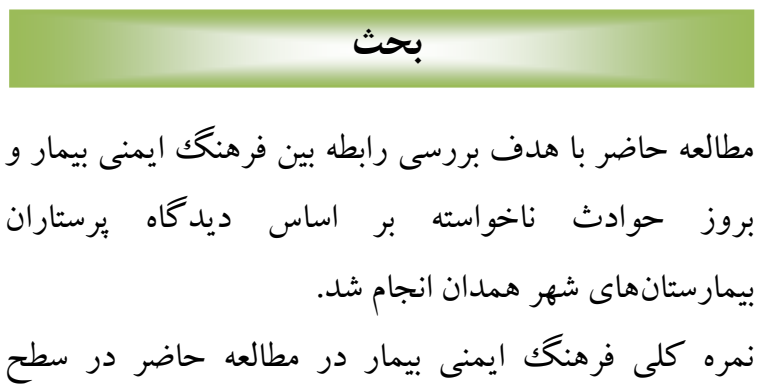

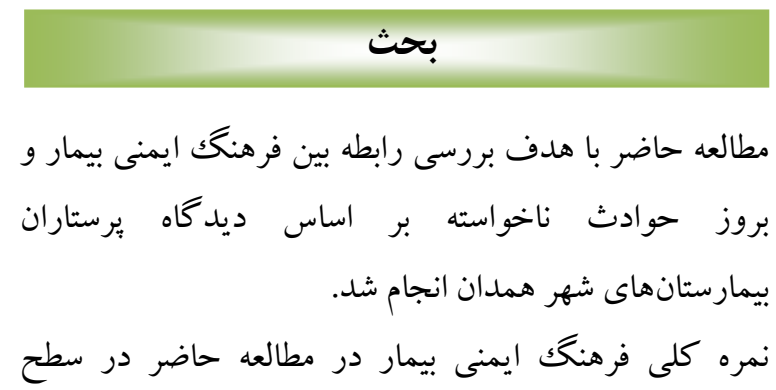

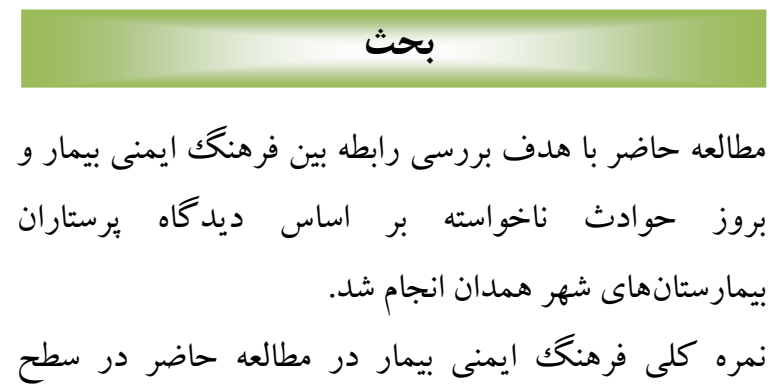

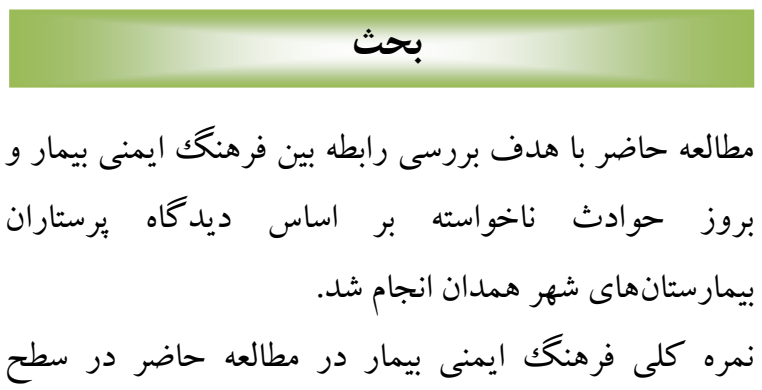

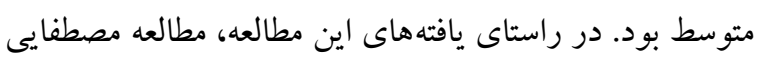

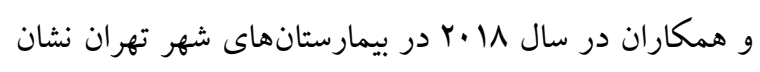

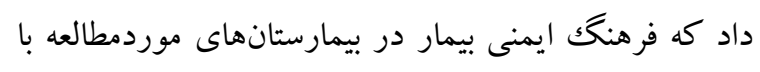

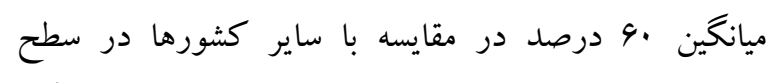

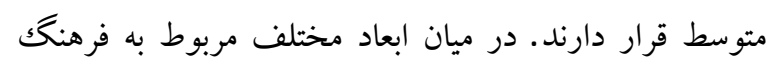

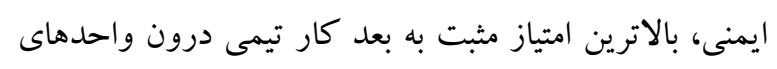




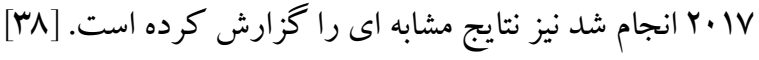
ايمنى بيمار بايد در بيمارستان و سازمانهاى مراقبت سلامت در اولويت قرار گيرد، زيرا بر بيماران و سازمانهاى مراقبت سلامت تأثير منفى مى گذارد. همجينين، ارتباطات نيز در موفقيت كار و تلاش تيمى بهخصوص ميان كار كنان مراقبت

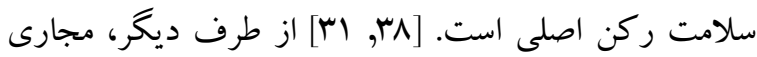
ارتباط ناكارآمد ممكن است منجر به نتايج منفى شود، همانطور كه در نمرات كم بهدست آمده در تبادل و انتقال اطلاعات منعكس شده است. در مطالعه الجاردلى و همكاران [\%؟] در كشور لبنان در سال

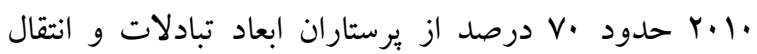
اطلاعات و نيز حمايت مديريت از ايمنى بيمار را بهعنوان ضعيفترين ابعاد در فرهنگ ايمنى بيمار دانسته و بر اين باور بودند كه پايين بودن ابعاد يادشده در فرهنگك ايمنى بيمار مى تواند در كاركنان برستارى تأثير اتى مانند تقويت روحيه در انجام كار در شرايط بحرانى و رسيدگى به حجم زيادى از كار را سلب كند. همجنين، طبق بررسى آيكن و همكاران [•.F] در

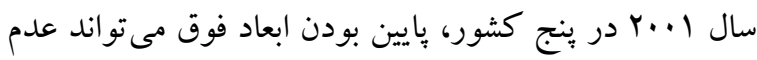

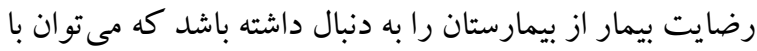
مديريت دقيق بر روى فرهنگك ايمنى بيمار و لحاظ كردن آن به نحو احسن اين عامل را به بهترين سطح خود رساند.

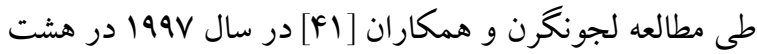
كشور، با انجام دستورالعملهاى استاندارد براى ابعاد فرهنگ ايمنى بيمار مىتوان بهصورت بركزارى دورههاى آموزشى مهارتهاى ارتباطى كاركنان يرستارى و مديران بخشها را تقويت نمود. همجينين، بر اساس مطالعه انجامگرفته توسط آيكن و همكاران [F[F] مهارت هاى ارتباطى و حمايت مديران در كشورهاى موردبررسى نظير (آمريكا / Fq درصد، كانادا

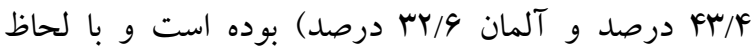
سيستم حمايت مديران از فرهنگك ايمنى بيمار مىتوان بهبود جشم گيرى در ابعاد فرهنگ ايمنى بيمار ايجاد كرد. نتايج مطالعه حاضر نشان داد كه شيوع حوادث ناخواسته در بين برستاران بالا است. بهطورى كه اكثريت برستاران تخمين
بيماران بيشتر تلاش كنند. همجِين، نويسند كان معتقد بودند بعضى از جالشهاى امنيتى بيمار با ارائهدهند گان مراقبتهاى بهداشتى خط مقدم در محل وقوع حل نمىشود و بايد به آنها در سطوح بالاتر سازمانها برداخته شود. در مطالعات انجام گرفته در كشورهاى ديخر مانند عربستان [ اس, •r[]، تر كيه

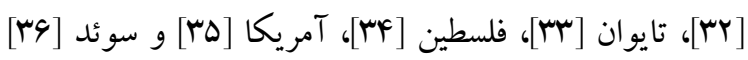
بعد كار تيمى درون واحدهاى بيمارستان و ياد گيرى سازمانى بهعنوان نقطه قوت فرهنگ ايمنى بيمار شناسايىشده بودند كه با يافته مطالعه حاضر همسو است. همجنين، مطالعه الاحمدى و همكار ان در سال •. · ب در كشور

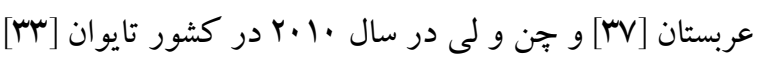
نشان داد كه از بين ابعاد فرهنگ ايمنى بيمار بالاترين ميانكين مربوط به بعد ياد كيرى سازمانى بوده است. علاوه بران، مطالعات فوق براى افزايش سطح درك فرهنگ ايمنى بيمار براى بيمارستانهاى خود دورههاى آموزشى و يادگيرى را مدنظر قرار داده و بر اهميت كار گروهى تأكيد فراوان داشتهاند. آنها بر اين باور بودند كه از اين طريق مىتوانند

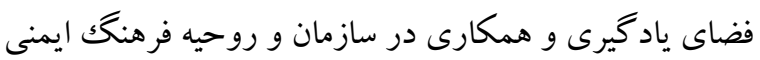
بيماران را ايجاد و تقويت كرده و با در دستور كار قرار دادن مديريت فرهنگ ايمنى بيمار اين برگك خريد مهم را تقويت كنتد. علاوه بر جّند نقطه قوت اشارهشده در مطالعه، از ديدكاه يرستاران تبادلات و انتقال اطلاعات، حمايت مديريت از ايمنى بيمار و باز بودن مجارى ارتباطى در بيمارستان بهعنوان نقطهضعف مطرح بودند. در مطالعهاى كه در كشور سوئد توسط دنيلسون و همكاران در سال Y.IV انجامشده است حمايت مديريت از ايمنى بيمار و كاركنان از نقاط ضعف فرهنك ايمنى بيمار بودند. [צr] در راستاى يافته هاى مطالعه حاضر، مطالعه الكويز و همكاران در سال 1 |+r در عربستان بين يرستاران نشان داد كه مهمترين نقطهضعف هاى فرهنك ايمنى بيمار باز بودن مجارى ارتباطات، تبادل و انتقال اطلاعات و يّاسخ غير تنبهى به خطاها هستند. [•r] يكك مطالعه مرورى در كشورهاى عربى كه توسط المونتسرى و همكاران در سال 
ارتباط معكوسى بين فرهنك ايمنى بيمار با عوارض ناشى از

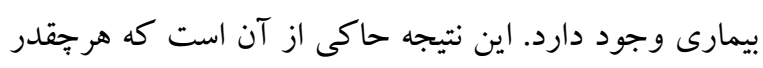

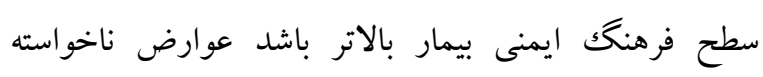

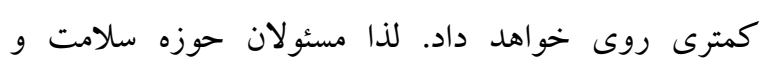

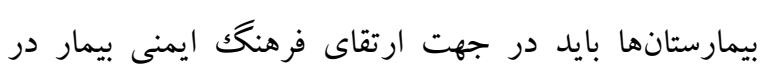

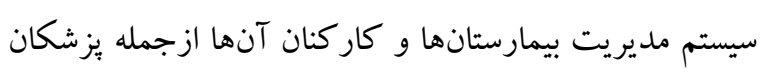

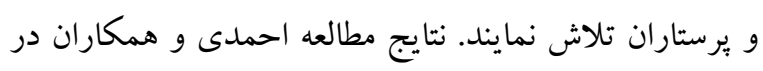

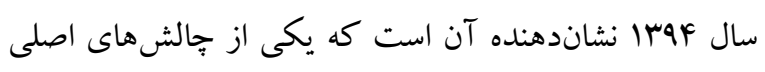

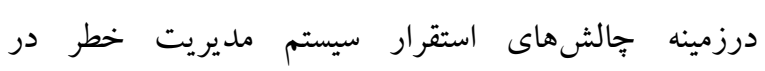

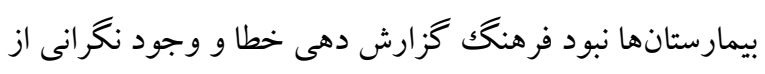
عواقب آن و همجينين عدم احساس نياز در يز شكان براى وارد فرد

شدن به اين حيطه است. [FY] مطالعات آينده مى تواند درزمينه بررسى علل و و عوامل مؤثر بر عملكرد ضعيف بيمارستان درزمينه گزارش دهى و يا عدم كزارش موارد حوادث ناخواسته توسط كاركنان، صورت

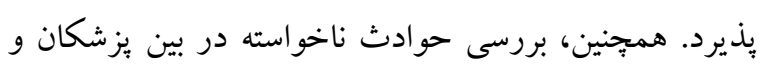

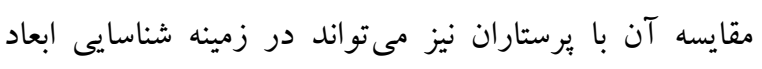
مختلف مؤثر بر گزارش دهى حوادث ناخواسته مفيد باشد.

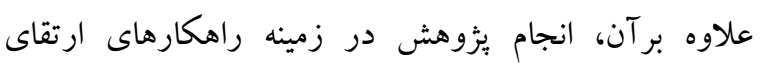

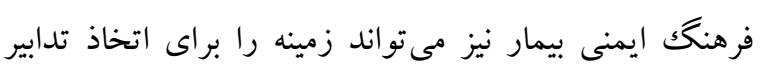
مؤثر در جهت ارتقاى آن فراهم آورد.

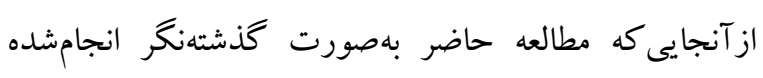

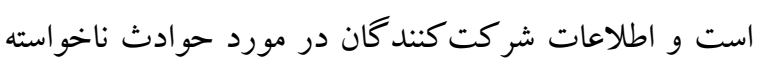

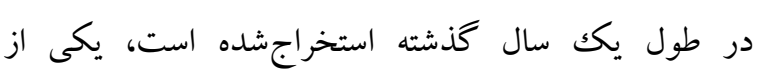
محدوديتهاى اين مطالعه تورش يادآورى است كه مى تواند

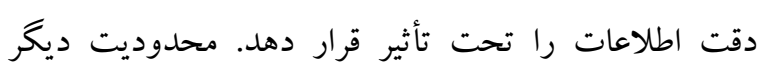

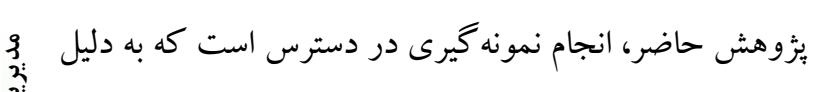

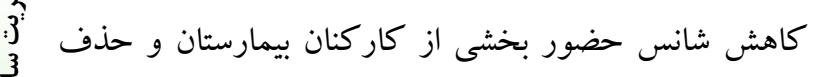

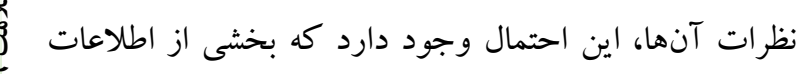

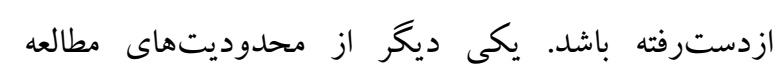

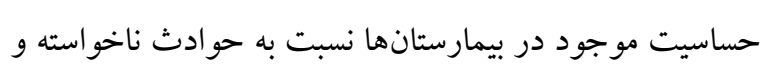

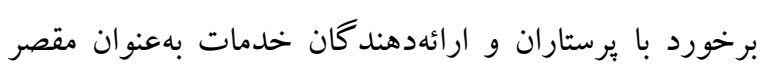

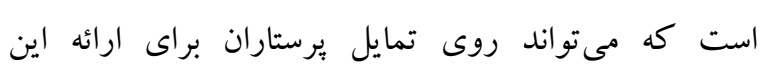

اطلاعات تأثير بحذارد.
زدهاند يككبار در سال حادثه ناخواسته براى آنها اتفاق افتاده

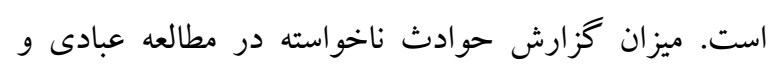

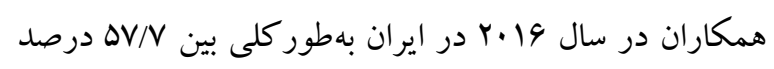

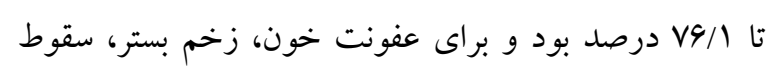

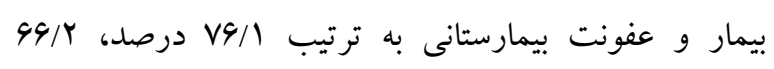

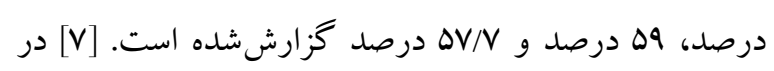

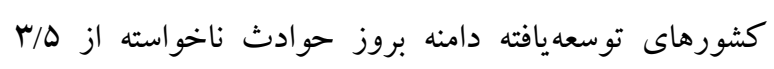

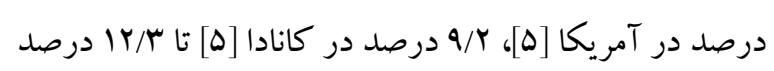
در سوئد [9] است. يافتهاى مطالعه وانكك و همكاران در سال

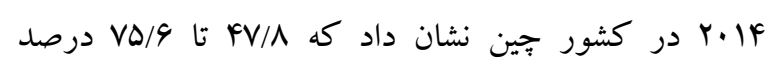
يرستاران تخمين زدند كه در يكك سال كذشته حوادث ناخواسته مختلف برايشان رخداده است. [19] در برخى مطالعات انجامشده در اين زمينه كليه كادر درمانى بران

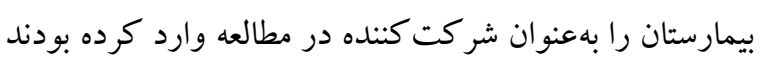

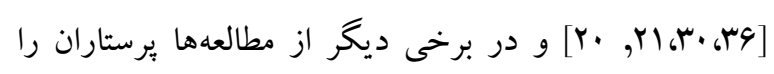

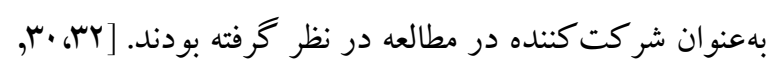
[V

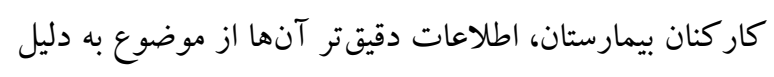
حضور بيشتر در بخش و ارتباط بيشتر با بيماران و همجينين

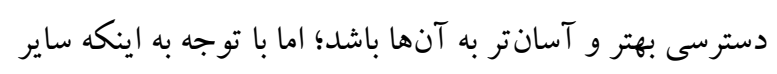

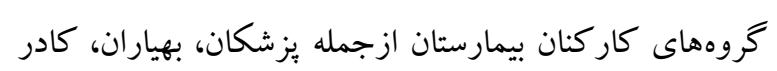

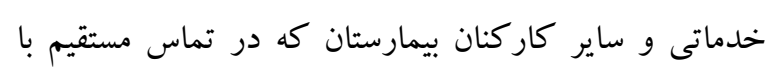
بيمار هستند نيز مى تواند اطلاعات دقيقى در مورد اين موضوع ليمان

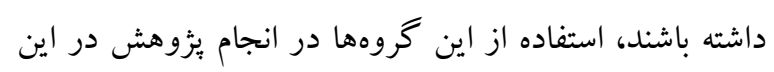
زمينه در جمع آورى اطلاعات دقيقتر مؤثر خواهد بود.

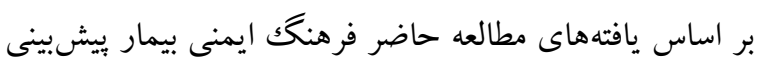
كننده معنى دار حوادث ناخواسته است. به اين معنى كه با بهبود فرهنك ايمنى بيمار ميزان بروز حوادث ناخواسته در بيمارستان

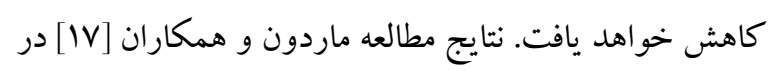

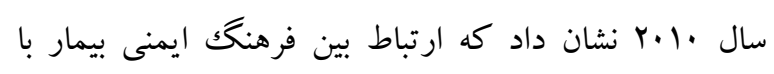

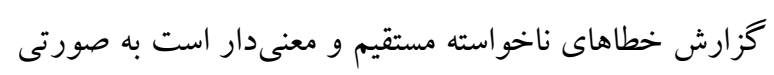
كه در بيمارستانهايى كه فرهنگك ايمنى بيمار بالاتر بوده، خطاهاى ناخواسته كمترى گزارش شده است. نتايج مطالعه

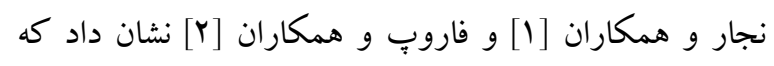


اخذشده از كميته اخلاق دانشگاه علوم يزشكى همدان

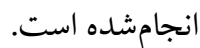

مسائل اخلاقى (ازجمله جلب رضايت آكاهانه از از شر كت كنند گان، سرقت ادبى، انتشار / يا تسليم دو كانه و غيره) توسط نويسند كان بهطور كامل رعايت شده است. همجِنين، اصول محرمانگى در مشخصات و اطلاعات افراد رعايت شده

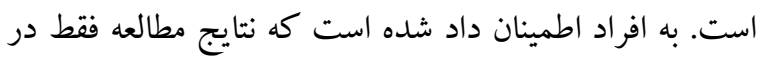
جهت اهداف مطالعه استفاده مىشود. همجنين، هريكك از افراد

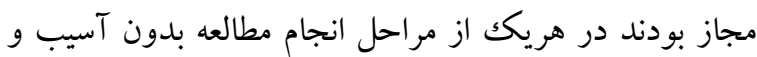
زيان مطالعه را ترك كنند. حمايت مالى: اين يزوهش با حمايت مالى دانشكاه علوم يزشكى همدان، همدان، ايران با شماره

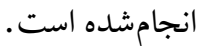

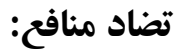
نو يسند گان اظهار داشتند كه تضاد منافعى وجود ندارد. تشكر و قدردانى: اين مقاله حاصل بخشى از طرح تحقيقاتى

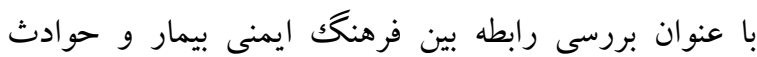
ناخواسته در بيمارستانهاى شهر همدان، مصوب معاونت تحقيقات و فن آورى دانشگاه علوم يزشكى همدان، در سال نويسندكان از معاونت تحقيقات و فن آورى دانشگاه علوم يز شكى همدان به خاطر تصويب و حمايت مالى از اين مطالعه در قالب طرح شماره AGIYrYAYGY تشكر و قدردانى مىنمايند. همجنين، از كليه شركت كنند كان در مطالعه و مسئولين بيمارستانهاى موردمطالعه تشكر و قدردانى مى شود.
استفاده از برستاران بهعنوان شركت كننده در مطالعه يكى از نقاط ضعف يُزوهش حاضر است. درصورتى كه حضور ساير كاركنان بيمارستان كه با بيمار در تماس مستقيم هستند خصوصاً يزشكان، بهياران، كاركنان خدمات و كاركنان بخشهاى تشخيصى امكان استخراج اطلاعات دقيق تر در اين

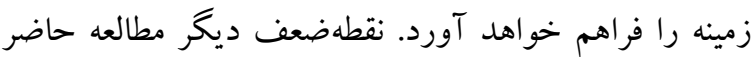
جمع آورى اطلاعات حوادث ناخواسته در قالب دو زمرينه

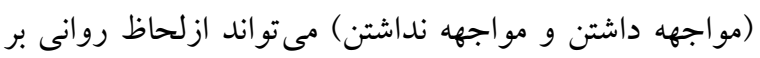

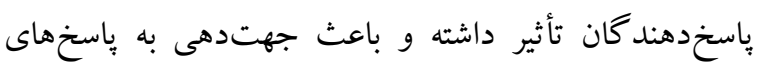

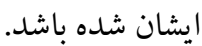
يافتهاى مطالعه حاضر نشان داد كه درك بر برستاران از فرهنك باند

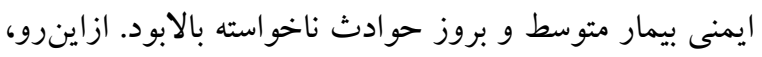
عواملى از قبيل حمايت مديران از ايمنى بيمار در بيمارستان،

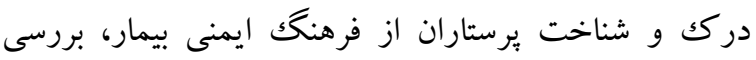

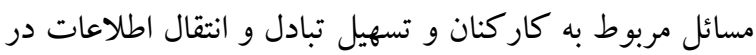
سازمان براى كاهش بروز حوادث ناخواسته ضرورى است

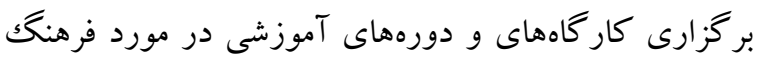

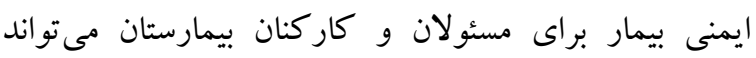

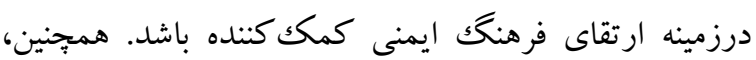

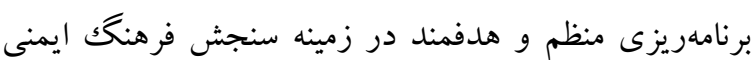

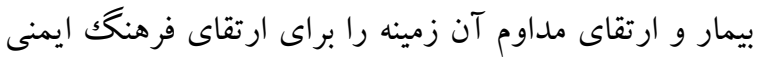
بيمار فراهم مى آورد. مطالعات بيشتر براى شناسايى مداخلاتى

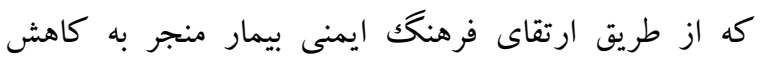

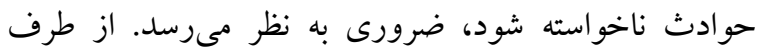
ديخر متوليان سلامت بايد از طريق روشهايى مثل تشويق

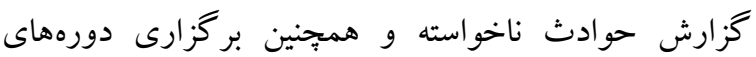
آموزشى براى برستاران زمينه را براى گزارش دهى حوادث

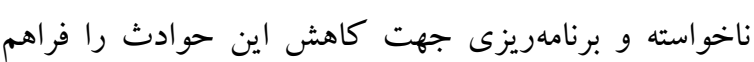
نمايند.

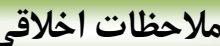

رعايت دستورالعملهاى اخلاقى: اين يزوهش با كد اخلاق به شماره IR.UMSHA.REC.1396.866 
1. Najjar S, Nafouri N, Vanhaecht K, Euwema M. The relationship between patient safety culture and adverse events: a study in Palestinian hospitals. Safety in Health. 2015;1(1):16.

2. Farup PG. Are measurements of patient safety culture and adverse events valid and reliable? Results from a cross sectional study. BMC Health Serv Res. 2015;15(1):186.

3. Zegers M, De Bruijne M, Wagner C, Hoonhout L, Waaijman R, Smits M, et al. Adverse events and potentially preventable deaths in Dutch hospitals: results of a retrospective patient record review study. Qual Saf Health Care. 2009;18(4):297-302.

4. Baker GR, Norton PG, Flintoft V, Blais R, Brown A, Cox J, et al. The Canadian Adverse Events Study: the incidence of adverse events among hospital patients in Canada .Can Med Assoc J. 2004;170(11):1678-86.

5. Wang $\mathrm{Y}$, Eldridge N, Metersky ML, Verzier NR, Meehan TP, Pandolfi MM, et al. National trends in patient safety for four common conditions, 2005-2011. N Engl J Med. 2014;370(4):341-51.

6. Soop M, Fryksmark U, Köster M, Haglund B. The incidence of adverse events in Swedish hospitals: a retrospective medical record review study. Int J Qual Health Care. 2009;21(4):285-91.

7. Abadi MBH, Akbari H, Akbari H, Gholami-Fesharaki M, Ghasemi M. The Association of Nursing Workloads, Organizational, and Individual Factors with Adverse Patient Outcome. Iran Red Crescent Med J. 2016;19(4).

8. Hogan H, Healey F, Neale G, Thomson R, Vincent C, Black N. Preventable deaths due to problems in care in English acute hospitals: a retrospective case record review study. BMJ Qual Saf. 2012;21(9):737-45.

9. James JT. A new, evidence-based estimate of patient harms associated with hospital care. J Patient Saf. 2013;9(3):122-8.

10. Levinson DR, General I. Adverse events in hospitals: national incidence among Medicare beneficiaries. Department of Health and Human Services Office of the Inspector General. Washington, DC: USA2010.

11. Hoonhout LH, de Bruijne MC, Wagner C, Zegers M, Waaijman R, Spreeuwenberg P, et al. Direct medical costs of adverse events in Dutch hospitals. BMC Health Serv Res. 2009;9(1):27.

12. Stefl M. To Err is Human: Building a Safer Health System in 1999. Front Health Serv Manage. 2001;18(1):1. 
13. Reason J. Human error: models and management. BMJ: British Medical Journal . $. V 9 \Lambda:(V Y T V) r Y \cdot ; r \cdots$

14. Woodward HI, Mytton OT, Lemer C, Yardley IE, Ellis BM, Rutter PD, et al. What have we learned about interventions to reduce medical errors? Annu Rev Public Health. 2010;31:479-97.

15. Singer S, Lin S, Falwell A, Gaba D, Baker L. Relationship of safety climate and safety performance in hospitals. Health Serv Res. 2009;44(2p1):399-421.

16. Wang X, Liu K, You L-m, Xiang J-g, Hu H-g, Zhang L-f, et al. The relationship between patient safety culture and adverse events: A questionnaire survey. Int J Nurs Stud. 2014;51(8):1114-22.

17. Mardon RE, Khanna K, Sorra J, Dyer N, Famolaro T. Exploring relationships between hospital patient safety culture and adverse events. J Patient Saf. 2010;6(4):226-32.

18. Ebadi fard azar F, Rezapoor A, Tanoomand Khoushehmehr A, Bayat R, Arabloo J, Rezapoor Z. Study of patients' safety culture in Selected Training hospitals affiliated whith Tehran university of medical sciences. Journal of Hospital. 2012;11(2):55-64.

19. Hatam N, Keshtkar V, Forouzan F, Bastani P. Patient safety culture status in teaching hospitals: a case of Shiraz University of Medical Sciences. Middle East J Sci Res. 2012;12(7):970-5.

20. Abdi Z, Delgoshaei B, Ravaghi H, Abbasi M, Heyrani A. The culture of patient safety in an Iranian intensive care unit. J Nurs Manag. 2015;23(3):333-45.

21. Rezaean M, Aqaie Borz Abad P, Yazdanpanah A, Zinat Motlagh S. Patient Safety Culture Status From The Perspective Medical Staff Of Yasuj Hospitals In 2015. Armaghane danesh. 2016;20(10):93546.

22. Almasi A, Pourmirza KR, Ahmadi JT, Godarzi A, Ahmadi A. Evaluation of patient safety culture in personnel of hospitals in Kermanshah, 2013. J Clin Res Paramed Sci. 2015;4(1):14-23.

23. Homauni A, Askari R, Shafiei M, Gharaei H, Fallah Zadeh H, Chalak M. Evaluation the effect of establishing patient safety friendly hospital initiative on improving patient safety culture in nurses views in Shahid Sadooghi University hospitals: A before and after study. Middle East J Sci Res. 2014;21(4):658-64.

24. Smits M, Christianns-Dingelhoff I, Wagner C, van der Wal G, Groenewegen W. The psychometric properties of the 'Hospital Survey on Patient Safety Culture' in Dutch hospitals. BMC Health Serv Res. 2008;8:230.

25. Sorra JS, Dyer N. Multilevel psychometric properties of the AHRQ hospital survey on patient safety culture. BMC Health Serv Res. 2010;10(1):199. 
حجت اله قرايى و همكاران

26. Moghri J, Ghanbarnezhad A, Moghri M, Rahimi Forooshani A, Akbari Sari A, Arab M. Validation of Farsi version of hospital survey on patient Safety culture questionnaire, using confirmatory factor analysis method. J Hosp. 2012;11(2):19-30.

27. Mostafaei D, Aryankhesal A, Dastoorpoor M, Rahimikhalifekandi Z, Estebsari F. Patient Safety Culture Assessment of Clinical and Paraclinical Staff Perspective in Selected University of Medical Sciences Hospitals in Tehran. Iran J Health Educ Health Promot. 2018;6(3):293-301.

28. Nordin A, Theander K, Wilde-Larsson B, Nordström G. Health care staffs' perception of patient safety culture in hospital settings and factors of importance for this. Open J Nurs. 2013;3(8A):28-40.

29. Singer SJ, Gaba D, Geppert J, Sinaiko A, Howard SKs, Park K. The culture of safety: results of an organization-wide survey in 15 California hospitals. BMJ Qual Saf. 2003;12(2):112-8.

30. Alquwez N, Cruz JP, Almoghairi AM, Al-otaibi RS, Almutairi KO, Alicante JG, et al. Nurses' perceptions of patient safety culture in three hospitals in Saudi Arabia. J Nurs Scholarsh. 2018;50(4):422-31.

31. El-Jardali F, Sheikh F, Garcia NA, Jamal D, Abdo A. Patient safety culture in a large teaching hospital in Riyadh: baseline assessment, comparative analysis and opportunities for improvement. BMC Health Serv Res. 2014;14(1):122.

32. Güneş ÜY, Gürlek Ö, Sönmez M. A survey of the patient safety culture of hospital nurses in Turkey. Collegian. 2016;23(2):225-32.

33. Chen I-C, Li H-H. Measuring patient safety culture in Taiwan using the Hospital Survey on Patient Safety Culture (HSOPSC). BMC Health Serv Res. 2010;10(1):152.

34. Hamdan M, Saleem AAo. Assessment of patient safety culture in Palestinian public hospitals. Int J Qual Health Care. 2013;25(2):167-75.

35. Wagner C, Smits M, Sorra J, Huang C. Assessing patient safety culture in hospitals across countries. Int J Qual Health Care. 2013;25(3):213-21.

36. Danielsson M ,Nilsen P, Rutberg H, Årestedt K. A National Study of Patient Safety Culture in Hospitals in Sweden. J Patient Saf. 2017;15(4):328-33.

37. Alahmadi H. Assessment of patient safety culture in Saudi Arabian hospitals. Qual Saf Health Care. 2010;19(5):e17-e.

38. Elmontsri M, Almashrafi A, Banarsee R, Majeed A. Status of patient safety culture in Arab countries: a systematic review. BMJ open. 2017;7(2):e013487. 
39. El-Jardali F, Jaafar M, Dimassi H, Jamal D, Hamdan R. The current state of patient safety culture in Lebanese hospitals: a study at baseline. Int J Qual Health Care. 2010;22(5):386-95.

40. Aiken LH, Clarke SP, Sloane DM, Sochalski JA, Busse R, Clarke H, et al. Nurses' reports on hospital care in five countries. Health Aff. 2001;20(3):43-53.

41. Ljunggren G, Phillips $C D$, Sgadari A. Comparisons of restraint use in nursing homes in eight countries. Age and ageing. 1997;26(suppl_2):43-7.

42. Ahmadi B, Keshvari M, Homauni A, Gharaei H. A Study on the Challenges Faced By Health Systems in Establishing Risk Management in Selected Hospitals of Tehran University of Medical Sciences. Journal of Patient Safety \& Quality Improvement. 2014;2(3):126-30. 